\section{Some psychophysiological and latency correlates of rule induction'}

MARJORIE F. ELIAS and SHELDON H. WHITE, Laboratory of Human Development, Harvard University, Cambridge, Mass. 02138

\begin{abstract}
Psychophysiological and latency measures associated with solution of a complex problem were studied. Twenty high-school Ss were given tasks requiring formulation of a rule for solution. Skin potential (SP), vasoconstriction $(V C)$, and response latency $(R L)$ were continuously measured. Comparing early and late measures on solved and unsolved tasks, it was found that: (1) response decrements did occur in all three measures in solved tasks; (2) they did not occur in unsolved tasks; (3) the difference in decrease between solved and unsolved tasks was significant for $S P$ and $R L$ but not for $V C$.
\end{abstract}

Although tasks and response measures have varied, a consistent decrease in autonomic reactivity has emerged whenever investigators have broken down their results into trials before learning has occurred (by whatever criterion they used) compared to trials afterwards. Germana (1968) has recently reviewed the literature. Studies which show the decrease in GSR amplitude were done by Kintsch (1965) and Obrist (1950) with nonsense syllable tasks, by Germana \& Pavlik (1964) in a multiplechoice problem, and by Grings \& Lockhart (1966) in a shock avoidance task. Another nonsense syllable study (Andreassi \& Whalen, 1967) found decrease in skin conductance level and GSR frequency. These decreases in autonomic reactivity seem to be paralleled by decreases in response latency. Studies have shown quickening of response after solution in three different learning tasks: reversal shifts (Erickson, Zajkowski, \& Ehmann, 1966), paired associates (Millward, 1964), and a card-sorting task (Siegel, 1964).

The purpose of the present study was to look for comparable autonomic and latency effects in a more complex problem-solving task. The tasks chosen for the study required the $S$ to induce a general rule from a series of specific instances: for example, given a series of pairs of numbers, it is always the even number that is correct. Generally speaking, the expectation guiding the study was that characteristic orienting-response measures might be expected to remain large during the presolution phase of rule-seeking, diminish- ing after an adequate rule has been established.

The response measures were palmar skin potential (SP), vasoconstriction of the finger (VC), and latency of response (RL). Recordings of these three measures were taken because, as above cited, reactivity on all three has been previously shown to be sensitive to learning, and because all three have been implicated as components of the orienting reaction (Sokolov, 1963; Berlyne, 1960).

\section{SUBJECTS}

Subjects were 20 public high school students in a college preparatory program, participating as paid volunteers. One was eliminated from analysis because she solved all the problems, and comparison between solved and unsolved tasks was not possible in her case. The analyses discussed here were derived from the remaining 19 records.

\section{TASK}

Eight problems were presented by slide projector. Each problem consisted of a series of 10 slides, each presenting two side-by-side words, numbers, or shapes. Seeing the two items, $\mathrm{S}$ had to choose one, and press one of two buttons on a panel in front of him to indicate a choice of the left or right item. Simultaneously with the button press, a light came on above the correct button to inform $\mathrm{S}$ of the correct choice. Response to the first item in each task had to be a guess, with $\mathrm{p}=.5$ of being correct. After finding the rule governing the task, $S$ could be correct every time on subsequent slides. The rules for the eight tasks were: (1) word meaning a liquid; (2) number that is a multiple of three; (3) capital letter containing an acute angle; (4) word with four letters; (5) prime number; (6) shape that is concave up (holds water); (7) word ending in "er"; (8) shape that is a rotation but not a reflection of the capital letter $F$.

\section{RECORDING APPARATUS}

Recording was done on a Grass Model 7 polygraph. SP was recorded as a dc measure with silver-silver chloride electrodes from the palm and the back of the forearm of the nondominant hand. VC was recorded with a Grass photoelectric plethysmograph from the index finger of the same hand. Slide presentations and responses were marked on the paper output of the polygraph along with the running physiological records. Grason-Stadler Series 1200 modules were used to program the task.
PROCEDURE

Electrodes were placed on $S$. Then instructions were given. He was told that he would be shown two items and would have to indicate which was correct. The first time he would have to guess, and after that he might be able to figure out a rule and be correct every time. There was no emphasis on time. $S$ was seated at a table in the room with $E$ and the polygraph. During the tasks, his back was turned to the equipment as he faced the wall on which slides were projected.

Four tasks were given, followed by a 5-min rest period to obtain autonomic resting levels, and then four more tasks. The procedure took about $45 \mathrm{~min}$ to complete. Since the first task was considered a practice task and not scored, electrodes were in place for about $15 \mathrm{~min}$ before the first scored responses were made. After each task $S$ was asked what rule, if any, he had found, when he had thought of it, and whether he had had any other guesses previously.

DATA ANALYSIS AND RESULTS

Tasks were classified as solved and the trial on which solution took place identified according to two criteria: no more errors, and S's verbal report of the rule and when he guessed it. Tasks were classified as unsolved if errors persisted and $S$ reported no rule or one which did not work. Tasks which could not be classified by both criteria were not scored. No $\mathrm{S}$ had more than one unscored task.

SP response was measured as maximal millimeter pen deflection in the $6 \mathrm{sec}$ after S's button press. VC response was the amplitude of the most constricted pulse during the same 6 sec. Response latency was measured in millimeters from slide onset to button press on paper moving at $3 \mathrm{~mm} / \mathrm{sec}$, giving accuracy of timing to $.33 \mathrm{sec}$.

For solved tasks, difference scores $(\Delta$ scores) were computed by subtracting the mean response on all trials after solving from the mean response on all trials before solving. The mean before solving included the solve response and excluded the first response of the task. As a control, $\Delta$ scores for unsolved tasks were computed by subtracting the mean response late in the task (to Slides 6-10) from the mean early in the task (to Slides 2-5). To eliminate the influence of individual differences in lability, scores in SP and VC were converted into standard scores $\Delta_{\mathrm{z}}$ by dividing each S's $\Delta$ score by his standard deviation of differences $(s \Delta)$. RL scores were transformed to $\log$ scores before averaging in order to normalize their distribution. Comparisons of $\Delta$ scores with zero were done by $t$ test (see Table 1). During solved tasks, there were significant decreases in response amplitude after solving for all measures. For SP and RL, this was not due 


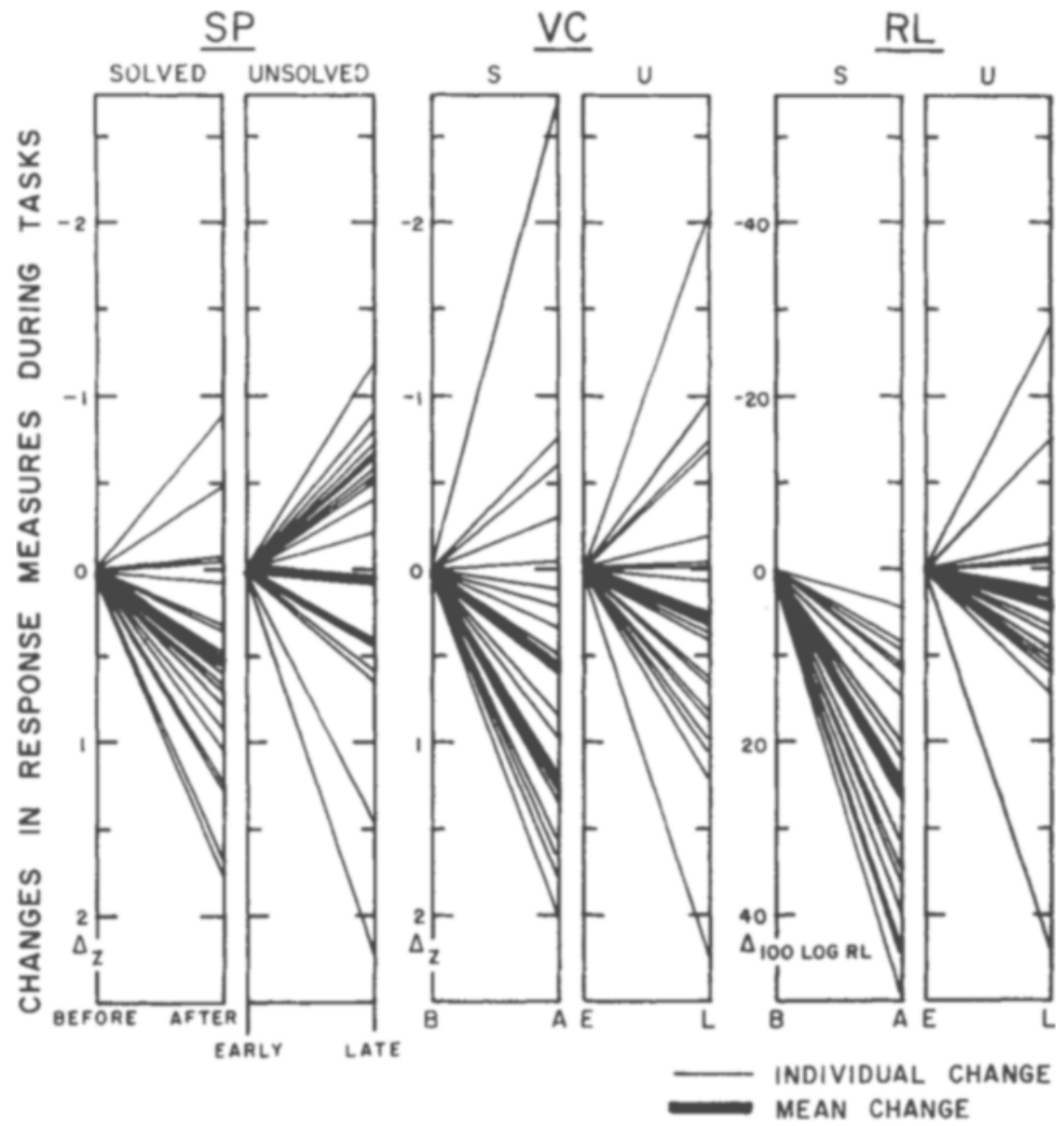

Figure 1

Table 1

Changes in Response Measures during Solved and Unsotved Tasks

\begin{tabular}{lccccccc}
\hline & $\begin{array}{l}\text { Solved } \\
\text { Before- } \\
\text { After }\end{array}$ & $\begin{array}{l}\text { SP } \\
\text { Unsolved } \\
\text { Early- } \\
\text { Late }\end{array}$ & $\begin{array}{l}\text { Solved } \\
\text { Before- } \\
\text { After }\end{array}$ & $\begin{array}{l}\text { VC } \\
\text { Unsolved } \\
\text { Early- } \\
\text { Late }\end{array}$ & $\begin{array}{l}\text { Solved } \\
\text { Before- } \\
\text { After }\end{array}$ & $\begin{array}{l}\text { RL } \\
\text { Unsolved } \\
\text { Early- } \\
\text { Late }\end{array}$ \\
\hline $\begin{array}{l}\text { Mean } \\
\text { Difference }\end{array}$ & .55 & .05 & .56 & .27 & 25.3 & 4.6 \\
SD & .56 & .85 & 1.09 & .92 & 12.9 & 13.5 \\
$\mathrm{t}$ & $4.28^{* *}$ & .27 & $2.24^{*}$ & 1.28 & $8.54^{* *}$ & 1.48 \\
\hline
\end{tabular}

$* p<.05$

$* p<.01$

Table 2

Comparison of Response Measures Late in Unsolved Tasks with Measures Before and After Solution in Solved Tasks

\begin{tabular}{lccccccc}
\hline & $\begin{array}{l}\text { Late- } \\
\text { Before }\end{array}$ & $\begin{array}{l}\text { SP } \\
\text { Late- } \\
\text { After }\end{array}$ & & $\begin{array}{l}\text { Late- } \\
\text { Before }\end{array}$ & $\begin{array}{l}\text { VC } \\
\text { Late- } \\
\text { After }\end{array}$ & $\begin{array}{l}\text { Late- } \\
\text { Before }\end{array}$ & $\begin{array}{l}\text { Late- } \\
\text { After }\end{array}$ \\
\hline $\begin{array}{l}\text { Mean } \\
\text { Difference }\end{array}$ & -.04 & .52 & -.81 & -.32 & .78 & 26.1 \\
SD & 1.1 & 1.11 & 1.03 & 1.33 & 15.3 & 16.93 \\
$t$ & -.16 & $2.04^{*}$ & $-3.43^{* *}$ & -1.04 & .22 & $6.72^{* *}$ \\
\hline
\end{tabular}

$*<<.05$

$* p<.01$ to a general decrement over the task because a comparable decrease did not occur in unsolved tasks.

When early-to-late changes for solved and unsolved tasks were compared by a t test of correlated means, SP showed a significant difference $(t=3.08, p<.01)$ as did $R L$ $(\mathrm{t}=4.68, \mathrm{p}<.01)$, but $\mathrm{VC}$ did not $(t=1.17, p>.05)$. For VC, then, one would have to infer a trend to diminishing responses related to the course of the task rather than specifically to solving.

If solution produced a decline in reactivity, late responses in unsolved tasks should be similar to "before" responses in solved tasks and different from "after" responses. Table 2 shows the results of relevant comparisons. The data pictured in Table 2 are consistent with the principle that response measures in the late part of unsolved tasks are similar to "before" measures on solved tasks for the two measures, SP and RL. The result strengthens the inference that observed early-to-late decreases on these measures were due to solving. In VC, however, late responses were more like those in the latter part of solved tasks, indicating that duration of the task affects reactivity more than solution.

\section{REFERENCES}

ANDREASSI, J. L., \& WHALEN, P. M. Some physiological correlates of learning and overlearning. Psychophysiology, 1967, 3, 406-413.

BERLYNE, D. E. Conflict, arousal, and curiosity. New York: McGraw-Hill, 1960.

ERICKSON, J. R., ZAJKOWSKI, M. M., \& EHMANN, E. D. All-or-none assumptions in concept identification: Analy sis of latency data. Journal of Experimental Psychology, 1966,72, 690-697.

GERMANA, J. Psychophysiological correlates of conditioned response formation. Psychological Bulletin, 1968, 70, 105-114.

GERMANA, J. J., \& PAVIIK, W. B. Autonomic correlates of acquisition and extinction. Psychonomic Science, 1964, 1, 109-1 10.

GRINGS, W. W., \& LOCKHART, R. A. Galvanic skin response during avoidance learning. Psychophysiology, 1966, 3, 29-34.

KINTSCH, W. Habituation of the GSR component of the orienting reflex during paired-associate learning before and after learning has taken place. Journal of Mathematical Psychology, $1965,2,330-341$.

MILLWARD, $R$. Latency in a modified pairedassociate learning experiment. Journal of Verbal Learning \& Verbal Behavior, 1964, 3, 309-316.

OBRIST, W. D. Skin resistance and electroencephalographic changes associated with learning. (Doctoral dissertation, Northwestem University) Ann Arbor, Mich.: University Microfilms, 1950. No. 66-1145.

SIEGEL, P. S. Concept formation: Response time considerations. Psychological Reports, 1964, 14, 435-442.

SOKOLOV, E. N. Perception and the conditioned reflex. New York: Macmillan, 1963.

\section{NOTE}

1. This research was supported by Grant 0E5-10-239 from the Office of Education. 